\title{
Plasmodium falciparum ookinete expression of plasmepsin VII and plasmepsin X
}

Fengwu $\mathrm{Li}^{\dagger}$, Viengngeun Bounkeua ${ }^{\dagger}$, Kenneth Pettersen and Joseph M. Vinetz ${ }^{*}$

\begin{abstract}
Background: Plasmodium invasion of the mosquito midgut is a population bottleneck in the parasite lifecycle. Interference with molecular mechanisms by which the ookinete invades the mosquito midgut is one potential approach to developing malaria transmission-blocking strategies. Plasmodium aspartic proteases are one such class of potential targets: plasmepsin IV (known to be present in the asexual stage food vacuole) was previously shown to be involved in Plasmodium gallinaceum infection of the mosquito midgut, and plasmepsins VII and plasmepsin X (not known to be present in the asexual stage food vacuole) are upregulated in Plasmodium falciparum mosquito stages. These (and other) parasite-derived enzymes that play essential roles during ookinete midgut invasion are prime candidates for transmission-blocking vaccines.
\end{abstract}

Methods: Reverse transcriptase PCR (RT-PCR) was used to determine timing of P. falciparum plasmepsin VII (PfPM VII) and plasmepsin X (PfPM X) mRNA transcripts in parasite mosquito midgut stages. Protein expression was confirmed by western immunoblot and immunofluorescence assays (IFA) using anti-peptide monoclonal antibodies (mAbs) against immunogenic regions of PfPM VII and PfPM X. These antibodies were also used in standard membrane feeding assays (SMFA) to determine whether inhibition of these proteases would affect parasite transmission to mosquitoes. The Mann-Whitney $\mathrm{U}$ test was used to analyse mosquito transmission assay results.

Results: RT-PCR, western immunoblot and immunofluorescence assay confirmed expression of PfPM VII and PfPM $X$ in mosquito stages. Whereas PfPM VII was expressed in zygotes and ookinetes, PfPM X was expressed in gametes, zygotes, and ookinetes. Antibodies against PfPM VII and PfPM X decreased P. falciparum invasion of the mosquito midgut when used at high concentrations, indicating that these proteases play a role in Plasmodium mosquito midgut invasion. Failure to generate genetic knockouts of these genes limited determination of the precise role of these proteases in parasite transmission but suggests that they are essential during the intraerythrocytic life cycle.

Conclusions: PfPM VII and PfPM X are present in the mosquito-infective stages of P. falciparum. Standard membrane feeding assays demonstrate that antibodies against these proteins reduce the infectivity of $P$. falciparum for mosquitoes, suggesting their viability as transmission-blocking vaccine candidates. Further study of the role of these plasmepsins in P. falciparum biology is warranted.

Keywords: Plasmodium falciparum, Plasmepsin, Aspartic protease, Transmission-blocking, Gene expression, Transcriptomics, Cell biology, Biochemistry

\section{Background}

Despite reduced incidence and mortality rates malaria continues to have a significant global impact with more

\footnotetext{
*Correspondence: jvinetz@ucsd.edu

${ }^{\dagger}$ Fengwu Li and Viengngeun Bounkeua contributed equally to this work Division of Infectious Diseases, Department of Medicine, University of California San Diego, 9500 Gilman Drive, La Jolla, CA 92093-0760, USA
}

than 200 million people infected and a reported 438,000 deaths in 2015 alone [1]. Malaria is initiated when sporozoites are injected into a human from the bite of a Plasmodium-infected anopheline mosquito, with severe disease most often due to Plasmodium falciparum. Increasing resistance to common anti-malarial drugs and the lack of an effective vaccine enhance the importance of malaria as a global scourge requiring new approaches, 
including novel vaccine approaches to simultaneously target multiple parasite stages [2]. In addition to sporozoite-targeting malaria vaccine approaches that aim to prevent initial human infection, complementary lines of malaria vaccine research have also focused on so-called transmission-blocking vaccines or, as newly articulated "vaccines that interrupt malaria transmission" [2], which aim to prevent humans with Plasmodium gametocytaemia from infecting the mosquito vector $[3,4]$. Transmission-blocking vaccines target proteins expressed on or secreted by sexual stage parasites, which develop in the mosquito midgut [5].

Anopheles species mosquitoes are the definitive hosts of Plasmodium parasites, which obligatorily complete development from sexual stages to sporozoites within the mosquito before transmission to humans. Upon ingestion by the mosquito, environmental changes encountered in the midgut stimulate mature gametocyte emergence from infected erythrocytes, in a process known as gametogenesis [6, 7]. Sexually dimorphic gametes fuse to generate zygotes in the midgut lumen. Zygotes then undergo sexual recombination and meiotic replication followed by transformation into polarized, motile ookinetes [8-10]. Ookinetes penetrate the midgut epithelium and form oocysts on the basal lamina. One ookinete that penetrates the midgut wall to form an oocyst has the potential to generate thousands of sporozoites, the form of the parasite that infects humans [11, 12]. Ookinete invasion of mosquito midgut is an important process for malaria transmission, but little is known about the molecular mechanisms involved.

Ookinetes produce stage-specific proteins important for subsequent midgut invasion, such as chitinase [13, 14], circumsporozoite- and thrombospondin-related adhesive protein [TRAP]-related protein (CTRP) [15, 16], von Willebrand A domain-related protein (WARP) [17, 18], Plasmodium 25/28 zygote/ookinete surface proteins (P25/28) $[9,19,20]$, secreted ookinete adhesive protein (SOAP) $[16,21]$, and membrane attack perforin (MAOP) [22] amongst others. Because proteases play important roles during parasite infection of and development in the mosquito, they were considered as potential transmission-blocking vaccine targets [23-28]. Transcriptomic data suggested that Plasmodium aspartic proteases, known as plasmepsins, are expressed in sexual stage parasites [29]. The P. falciparum genome encodes ten Plasmodium aspartic proteases known as plasmepsins [30]. Plasmepsins I, II, IV and HAP are present in the asexual blood stage parasite food vacuole and are involved in haemoglobin degradation in the food vacuole of blood stage parasites [30-35]. In the endoplasmic reticulum of asexual blood stage parasites, Plasmepsin V processes proteins and directs export of effector proteins
[36]. Plasmepsin VI plays an as-yet undefined but important role in parasite sporogonic development, particularly in early oocyst development in Plasmodium berghei [37]. Plasmepsin IV, in addition to its known role in haemoglobin degradation, is involved in Plasmodium ookinete invasion of the mosquito midgut [38].

Transcriptomic data have shown that $P$. falciparum plasmepsin VII (PfPM VII) mRNA is present in gametocytes, and plasmepsin X (PfPM X) mRNA is present during both in gametocytes and in zygotes and ookinetes [29]. The biological functions of PfPM VII and PfPMX remain unknown. Based on these observations, this study aimed to test the hypothesis that PfPM VII and PfPM $\mathrm{X}$ are targets of blocking mosquito midgut infection by $P$. falciparum. Such data would support the notion that these proteins would contribute to the interaction of the $P$. falciparum ookinete with the anopheline midgut and provide the basis for further development of these molecules as components of a malaria transmission-blocking vaccine.

\section{Methods}

\section{Parasites and mosquitoes}

Plasmodium falciparum strain NF54 from a master cell bank was used in this study, kindly provided under a material transfer agreement with Sanaria, Inc, Rockville, MD, USA. Parasites were maintained in asexual culture according to standard protocol [39]. Gametocytes and gametes were cultured in vitro according to the Ifediba and Vanderberg [40] modification of the Trager and Jensen method [41]; zygotes and ookinetes were cultured and purified as described [42-44].

Anopheles gambiae and Anopheles stephensi used in this study were a generous gift from Dr. Anthony James (University of California Irvine, Irvine, CA USA). Mosquitoes were maintained in an enclosed insectary at $26^{\circ} \mathrm{C}$ and $80 \%$ humidity with an automated 12-h light-dark cycle according to standard CDC protocol [45]. Mosquitoes used in this study were closely monitored and controlled according to the protocol for non-vertebrate animal subjects approved by the UCSD Institutional Animal Care and Use Committee (IACUC).

\section{DNA/RNA isolation and RT-PCR}

Plasmodium parasites were either generated in vitro or isolated ex vivo from infected mosquitoes. For ex vivo-isolated mosquito-stage parasite samples, midguts from mosquitoes were dissected and homogenized; five midguts were pooled per sample at $24 \mathrm{~h}$ post-engorgement. Genomic DNA was isolated using NucleoSpin Blood (Macherey-Nagel, Bethlehem, PA, USA). Total RNA was isolated using RNeasy (Qiagen, Valencia, CA, USA) and contaminating DNA was 
removed using DNA-free (Ambion, Austin, TX, USA) according to manufacturer's instructions. Reverse transcription was completed using gene-specific primers for PfPM VII, PfPM X and Pfs25 with SuperScript III first-strand synthesis system (Invitrogen, Carlsbad, CA, USA) according to manufacturer's instructions. PCR on resulting CDNA was done using Platinum PCR SuperMix High Fidelity (Invitrogen, Carlsbad, CA, USA) with $250 \mathrm{nM}$ of the same gene-specific primers for: Pfs25 (Fwd 5'-tgcgaaagttaccgtggatactg-3'; Rev $5^{\prime}$-tgcgaaagttaccgtggatactg-3'), PfPM VII (Fwd 5'-gcgcc atgggtaaaaatgaagaattcacgaatccttattcc- $3^{\prime}, \operatorname{Rev} 5^{\prime}$-gcgctc gagccttaaggttacatttcttttacttctaac- $3^{\prime}$ ) and PfPM X (Fwd $5^{\prime}$ - gtgatgaagaaagttacgttatatttgacacagg- $3^{\prime} ; \operatorname{Rev} 5^{\prime}$-gctctt gctactccaaccatagaagg- $\left.3^{\prime}\right)$. Thirty-five cycles were run with an annealing temperature of $55{ }^{\circ} \mathrm{C}$ and an extension temperature of $68^{\circ} \mathrm{C}$.

\section{Production of recombinant PfPM VII and PfPM X in Escherichia coli}

PfPM VII and PfPM X genes were amplified from genomic NF54 DNA to generate a gene that lacked the signal peptide. PCR products were gel purified on a $0.8 \%$ agarose gel using the PureLink gel extraction kit (Invitrogen, Carlsbad, CA, USA), ligated into pCR4-TOPO (Invitrogen, Carlsbad, CA, USA), transformed into Top10 competent cells (Invitrogen, Carlsbad, CA, USA) and sequence-verified (Eton Bioscience, San Diego, CA, USA). PfPM VII and PfPM X genes were then cloned into expression vectors pET32 and pGEX 4T-1 (GE Healthcare, Piscataway, NJ, USA), respectively.

The recombinant PfPM VII-HIS-tagged (rPfPM VIIHIS) and PfPM X-GST-tagged (rPfPM X-GST) fusion proteins were expressed in Rosetta (Merck/Novagen, Darmstadt, Germany) competent cells according to standard protocol [46]. Briefly, competent cells were transformed with 250-500 ng of purified plasmid DNA, streaked on LB agar plates embedded with $100 \mu \mathrm{g} / \mathrm{ml}$ ampicillin and allowed to grow overnight at $37^{\circ} \mathrm{C}$. Fresh colonies were inoculated and grown to $\mathrm{OD}_{600} 0.5-1$. Protein expression was then induced with $0.3 \mathrm{mM}$ isopropyl $\beta$-D-1-thiogalactopyranoside (IPTG) for $0.5-18 \mathrm{~h}$ at $18{ }^{\circ} \mathrm{C}$.

For rPfPM VII and rPfPM X protein verification, inclusion bodies were purified using BugBuster extraction reagent (Merck/Novagen, Darmstadt, Germany) and run on a 4-20\% Tris-Glycine SDS-PAGE gel that was then stained with Coomassie blue. A stained SDS-PAGE gel slice consistent with the predicted size of rPfPM VII-HIS and rPfPM X-GST fusion protein was excised and processed for mass spectrometry analysis (The Scripps Research Institute, La Jolla, CA, USA). The gel slices were destained and proteins were reduced with $10 \mathrm{mM}$ DTT, alkylated with $55 \mathrm{mM}$ iodoacetamide and digested in-gel with trypsin as previously described $[47,48]$. Samples were analysed by mass spectrometry, and identified peptides were searched by BLAST against the P. falciparum genome.

\section{Production of monoclonal antibodies against PfPM VII and PfPM $X$}

PfPM VII peptide sequences EEFTNPYSIRKKDI, IQPDEQSEEDNVDG, and KIGFVRSKRNVTLR were derived from predicted immunogenic regions of the PfPM VII protein sequence using resources freely available from the Immune Epitope Database (iedb.org). PfPM X peptide sequences KKLQKHHESLKLGDVKYYV, VRNQTFGLVESES, and LKESYWEVKLD were derived from predicted immunogenic regions of the PfPM X protein sequence (Fig. 1). These synthetic peptides were created with an $\mathrm{N}$-terminal cysteine to facilitate coupling to bovine serum albumin (BSA) as the antigenic carrier protein. Peptide composition was confirmed by mass spectrometry, and HPLC-purified peptides were used to immunize mice. The resulting hybridoma supernatants were screened against three sets of BSA-conjugated synthetic peptides, the same used to immunize mice, by enzyme linked immunosorbent assay (ELISA; A\&G Pharmaceuticals, Columbia, MD, USA). Secondary screening of ELISA-positive supernatant was performed by western immunoblot assay against full-length rPfPM VII-HIS or rPfPM X-GST. Hybridoma lines generating $\mathrm{mAb}$ that screened positive in both ELISA and Western immunoblot assays were grown in Dulbecco's modified eagle medium (DMEM, CellGro, Herndon, VA, USA) supplemented with $10 \%$ fetal calf serum. Antibodies were either concentrated from hybridoma supernatant or purified $\mathrm{mAb}$ in PBS (A\&G Pharmaceuticals, Columbia, MD, USA).

After screening against rPfPM VII, two lines, 1B4 and 2B1, generated antibodies directed against each catalytic domain of PfPM VII. After screening against rPfPM $\mathrm{X}$, one line, 6A9, generated antibody directed against the pro-enzyme domain, and one line, 3G6, generated antibody directed against the catalytic domain (Fig. 2). mAb 6A9 was directed against a peptide region unique to PfPM X while $3 G 6$ is directed against a peptide region that is moderately conserved with PfPM IX (Fig. 2).

\section{Immunofluorescence assay}

Fixed, permeabilized P. falciparum gametocytes, gametes, zygotes and ookinetes were analysed by IFA. Parasites were fixed on glass slides with $100 \%$ acetone at $-20{ }^{\circ} \mathrm{C}$ for at least $20 \mathrm{~min}$ and then rehydrated by two changes of PBS for $5 \mathrm{~min}$ each at room temperature. For membrane permeabilization and blocking of nonspecific binding, fixed cells were incubated in PBS supplemented 


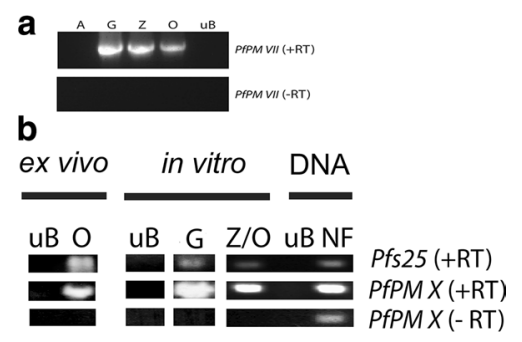

Fig. 1 Plasmepsin VII and Plasmepsin X mRNA was detected in Plasmodium falciparum sexual stage parasites. a Total RNA isolated from in vitro-cultivated asexual stages (A), gametocytes $(G)$, zygotes $(Z)$, ookinetes $(O)$, and uninfected human erythrocytes (UB). Samples were reverse transcribed and amplified using primers specific for PfPM VII (+RT). Samples that were not reverse transcribed (-RT) and amplified with PfPM VII-specific primers did not generate PCR product. b Total RNA isolated ex vivo from ookinete-containing mosquito midguts $(\mathrm{O})$ or uninfected human blood (UB), in vitro-cultivated gametocytes $(\mathrm{G})$ and mixed zygotes and ookinetes ( $\mathrm{Z} / \mathrm{O})$, as well as DNA from $P$. falciparum (NF) was isolated. Samples were reverse transcribed and amplified using primers specific for PfPM X and pfs 25 (+RT). Samples that were not reverse transcribed (-RT) and amplified with PfPM X-specific primers did not generate PCR product

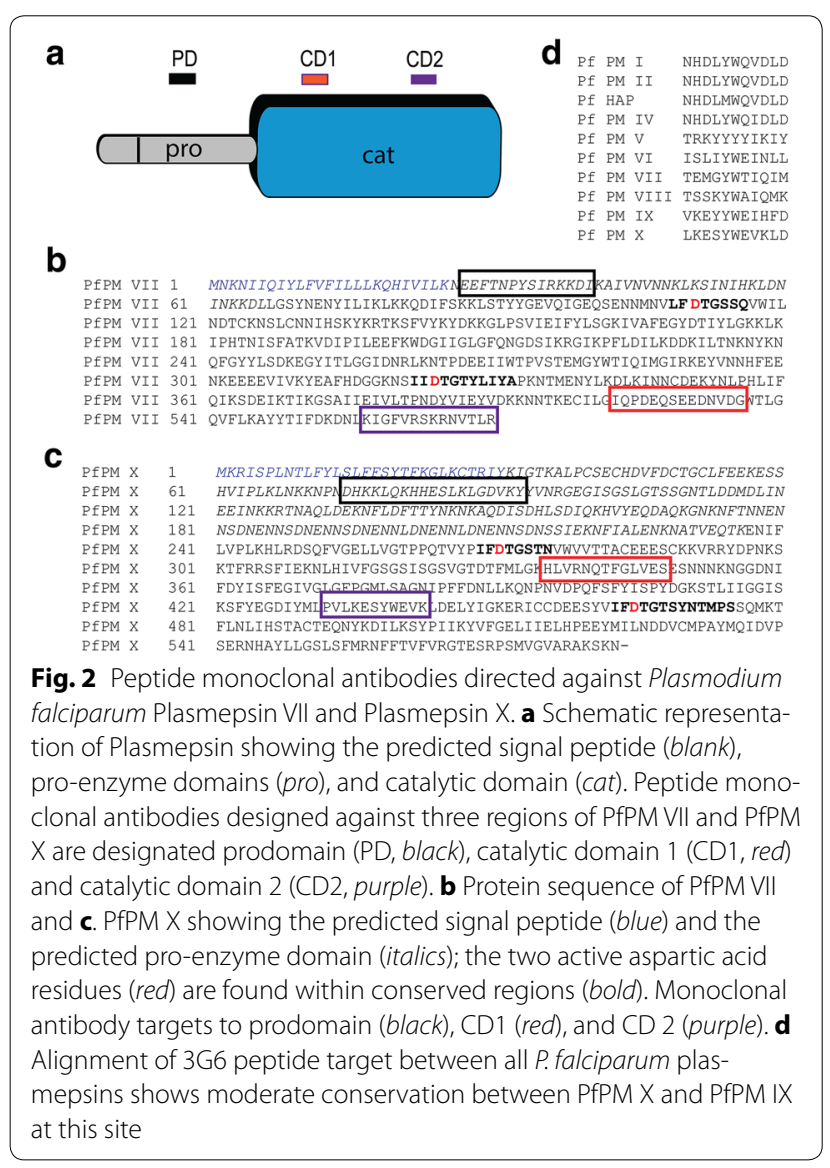

with $3 \%$ bovine serum albumin and $0.1 \%$ Triton X-100 for $1 \mathrm{~h}$ at room temperature. The preparations were then incubated with $\mathrm{mAb}$ (1:1000 dilution) for $1 \mathrm{~h}$ at room temperature followed by either FITC-conjugated antimouse IgG or Alexa Fluor 488 rabbit anti-mouse IgG (1:200 dilution) (Molecular Probes, Invitrogen, USA). Nuclei were visualized with 300 nM DAPI (4, 6-diamidino-2-phenylindole) (Pierce Biotechnology, Rockford, IL, USA). Slides were washed an additional six times in Tris-buffered saline (TBS) for a total of $30 \mathrm{~min}$ then mounted with coverslips using Dako mounting medium (Dako, Carpinteria, USA). Preparations were examined by deconvolution microscopy using an Olympus BX51 fluorescence microscope and Olympus DP71 camera (Olympus, Center Valley, CA, USA).

\section{Immunoelectron microscopy localization of PfPM VII and PfPM $X$}

Cells were fixed with $2.5 \%$ glutaraldehyde in $0.1 \mathrm{M}$ cacodylate buffer for $2 \mathrm{~h}$ at room temperature, postfixed in $1 \% \mathrm{OsO}_{4}$ in $0.1 \mathrm{M}$ cacodylate buffer $(1 \mathrm{~h})$ at room temperature, and embedded in LX-112 (Ladd Research, Williston, VT), as described previously [49]. Cryosections were made, applied to grids, blocked in $1 \% \mathrm{BSA}$ in PBS for $1 \mathrm{~h}$, incubated in 1:500 dilution of $\mathrm{mAb}$ against PfPM VII, PfPM X or IgG isotype control, washed and incubated with anti-mouse IgG conjugated to $5 \mathrm{~nm}$ colloidal gold particles as described previously [50]. Stained sections were examined using a Philips CM-10 electron microscope.

\section{Western immunoblot analysis}

Plasmodium falciparum parasites were purified, pelleted and resuspended in $250 \mu \mathrm{l}$ of lysis buffer (4 M urea, $0.4 \%$ Triton X-100, $50 \mathrm{mM}$ Tris, $5 \mathrm{mM}$ EDTA, $10 \mathrm{mM}$ $\mathrm{MgSO}_{4}, \mathrm{pH}$ 8.0) supplemented with Complete protease inhibitor cocktail (Roche Applied Sciences, Indianapolis, IN, USA). Parasites were processed by three cycles of freeze-thaw lysis followed by sonication on ice for $5 \mathrm{~min}$ in $30 \mathrm{~s}$ bursts using a Misonix Sonicator 3000 with an output setting of 7 (Misonix, Farmingdale, NY, USA). Protein concentrations were determined by BCA assay (Bio-Rad, Hercules, CA, USA). $100 \mu \mathrm{g}$ of each sample was mixed with Laemmli SDS-loading buffer $(160 \mathrm{mM}$ Tris, $10 \%$ SDS, $20 \%$ glycerol, $5 \% 2$-mercaptoethanol, $0.01 \%$ bromophenol blue, $\mathrm{pH} 8.0$ ) and boiled for $10 \mathrm{~min}$. Proteins were separated on Novex 10-20 \% SDS-PAGE mini-gels (Invitrogen, Carlsbad, CA 92008 USA) and transferred to nitrocellulose membranes. Membranes were blocked in TBS $/ 5 \%$ non-fat milk/0.05 \% Tween-20, 
$\mathrm{pH} 8.0$ for $1 \mathrm{~h}$. Blots were probed with primary antibody diluted 1:2000 in blocking buffer for $1 \mathrm{~h}$. Following six 10-min washes in blocking buffer, blots were probed with peroxidase-conjugated anti-mouse secondary antibody diluted 1:20,000 in blocking buffer. Blots were washed six times in blocking buffer, twice in TBS and then developed with chemiluminescent substrate (KPL, Gaithersburg, MD, USA).

\section{Membrane feeding assays}

Standard membrane feeding assays (SMFA) were performed to determine the ability of antibodies against Pf PMVII and PfPMX to affect infectivity of $P$. falciparum for mosquitoes. One day prior to the assay, female An. stephensi or An. gambiae mosquitoes aged 3-7 days post-emergence were segregated into cartons of 40-60 mosquitoes, and starved overnight. Mature $P$. falciparum gametocytes were examined for their ability to exflagellate and only those cultures with at least 10 exflagellating centres per 40X field were used for SMFA. Cultures with mature gametocytes were mixed with fresh human serum and red blood cells, plus antibodies, then fed to $A n$. stephensi or An. gambiae using water-jacketed glass membrane feeders as previously described [14]. Isotype immunoglobulin G2b (IgG2b) was used as a negative control. Twenty minutes after the start of the feed, membrane feeders were disengaged and non-engorged mosquitoes were removed from cartons. P. falciparum-infected mosquitoes were kept in a secured incubator separate from non-infected mosquitoes. Infected mosquitoes were fed with $8 \%$ fructose $/ 0.05 \% \mathrm{p}$-aminobenzoic acid in sterile water ad libitum and maintained at $26-28{ }^{\circ} \mathrm{C}$ and $80 \%$ relative humidity [51, 52].

On day 8-10 post blood meal, mosquito midguts were dissected, stained with mercurochrome and examined with a light microscope for the presence of oocysts [52]. All manipulations were done in accordance with UCSD IACUC-approved protocol for nonvertebrate research animals. Differences in infection rate and geometric means between test $\mathrm{mAb}$ and negative control groups were assessed using the nonparametric Mann-Whitney U test. Samples were considered to be statistically significant at a $p$ value $\leq 0.01$.

\section{Results}

PfPM VII and PfPM X mRNA was transcribed in P. falciparum sexual stages

RT-PCR of RNA isolated from P. falciparum sexual stage parasites generated in vitro and dissected from mosquitoes ex vivo demonstrated that PfPM VII and PfPM X
mRNA was detected in gametocytes and mixed zygotes/ ookinetes (Fig. 1). Conventional PCR of RNA samples not treated with reverse transcriptase did not produce PCR product and demonstrated that RNA samples were DNA free (Fig. 1).

\section{PfPM VII and PfPM X protein expression in sexual stage parasites}

IFA of $P$. falciparum sexual stage parasites using mAbs directed against PfPM VII and PfPM X demonstrated diffuse, cytoplasmic localization in P. falciparum zygotes and ookinetes but not gametocytes (Fig. 3). Neither PfPM VII nor PfPM X were found to be localized within specific sub-cellular compartments, such as micronemes or endoplasmic reticulum, or the ookinete cell surface as determined by immunoelectron microscopy.

Western immunoblot confirmed IFA results demonstrating PfPM VII and PfPM X protein expression in sexual stage parasites. Antibody 2B1 recognized a single $\sim 46 \mathrm{kDa}$ band in ookinetes but no other sexual stage parasite; this protein is close to the predicted $52 \mathrm{kDa}$ size of the full length protein and the $42 \mathrm{kDa}$ size of the PfPM VII catalytic domain (Fig. 3). Antibodies 6A9 and $3 \mathrm{G} 6$ recognized multiple bands in mixed gamete/zygote samples and ookinete samples, but not gametocyte samples. Antibody $6 \mathrm{~A} 9$ recognized two bands: a $56-60 \mathrm{kDa}$ protein, consistent with the predicted $61 \mathrm{kDa}$ size of full length PfPM X, and a faint 17-25 kDa protein, consistent with the predicted $23 \mathrm{kDa}$ size of the PfPM X pro-enzyme domain. Antibody $3 \mathrm{G} 6$ also recognized a $56-60 \mathrm{kDa}$ protein in addition to a faint $32-40 \mathrm{kDa}$ protein, consistent with the predicted $36 \mathrm{kDa}$ size of the catalytic domain. Of note, 6A9 and $3 \mathrm{G} 6$ recognized two bands in parasite lysate, one at $42-55 \mathrm{kDa}$ and the second at $27-30 \mathrm{kDa}$; these bands were also recognized by IgG isotype control antibody, indicating that these protein bands are nonspecific (Fig. 3).

\section{Antibodies directed against PfPM VII or PfPM X moderately decreased Plasmodium falciparum transmission to Anopheles in SMFAs}

To determine whether antibodies against either PfPM VII or PfPM X could affect $P$. falciparum transmission to mosquitoes, female An. stephensi and An. gambiae were fed infectious gametocytes mixed with 1B4, 2B1, 6A9, $3 \mathrm{G6}$ or isotype IgG negative control antibodies, respectively, in SMFAs (Table 1,2). Mosquito midguts were dissected 8-10 days post-blood meal to determine prevalence and intensity of infection.

The presence of antibodies directed against either PfPM VII or PfPM X in an infectious blood meal significantly decreased $P$. falciparum transmission to mosquitoes at high antibody concentrations (Tables 1, 2). 


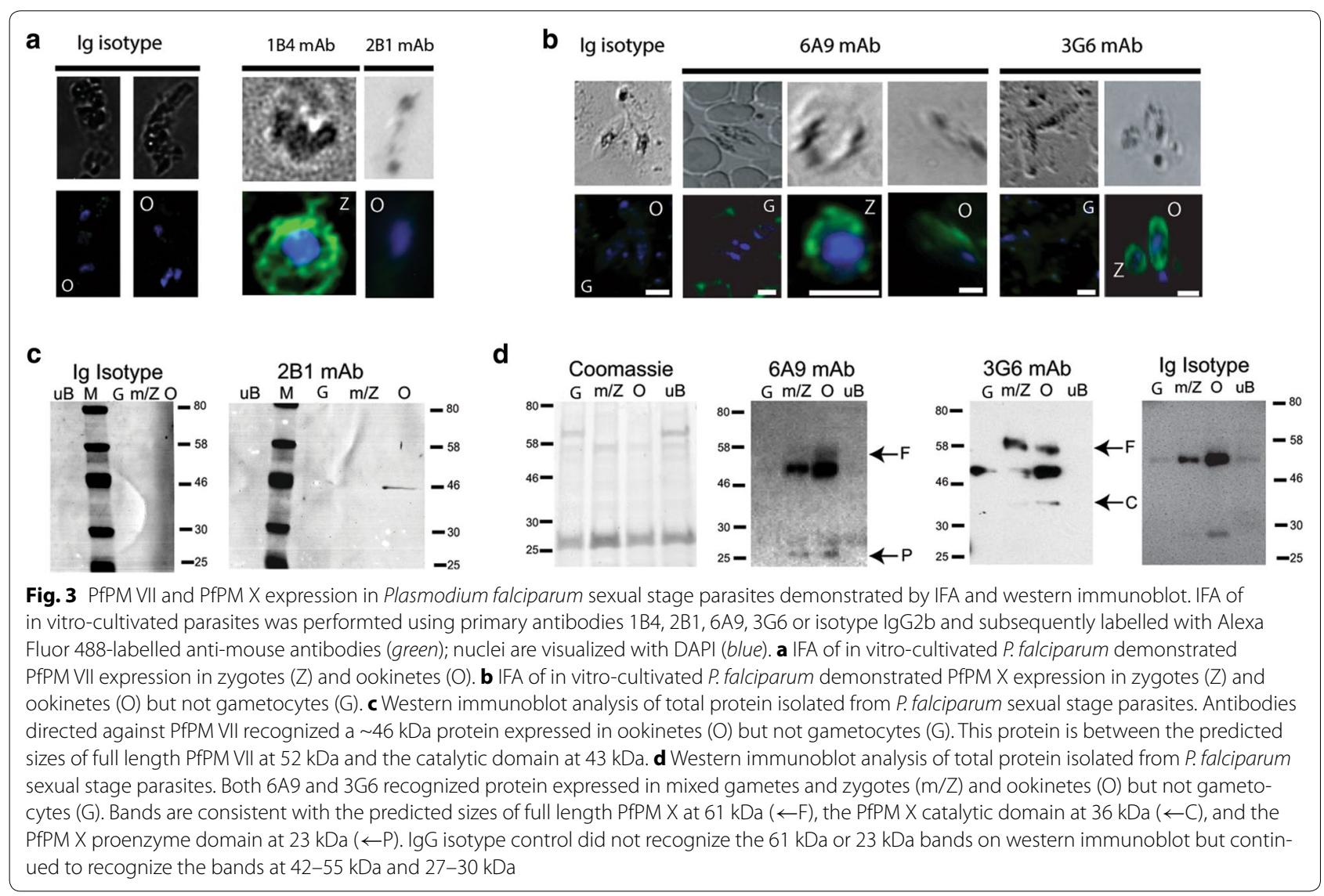

Mosquitoes fed an infectious bloodmeal with $200 \mu \mathrm{g} /$ $\mathrm{ml}$ of $1 \mathrm{~B} 4$ or $400 \mu \mathrm{g} / \mathrm{ml}$ of $2 \mathrm{~B} 1$ had a $35-71.4$ or $9.7-$ $23.5 \%$ reduction in prevalence compared to groups fed with IgG isotype control antibody (Table 1). Additionally, oocyst intensity of infected mosquitoes fed with1B4 or 2B1 was reduced by $81-97$ or $56-65 \%$ compared to IgG isotype control ( $p$ value $<0.01)$ (Table 1$)$. Mosquitoes fed an infectious blood meal with 100 or $200 \mu \mathrm{g} / \mathrm{ml}$ of $3 \mathrm{G} 6 \mathrm{had}$ a 18 or $33 \%$ reduction in prevalence compared to IgG isotype control (Table 2). Additionally, the oocyst intensity of infected mosquitoes fed with $100 \mu \mathrm{g} /$ $\mathrm{ml}$ of $3 \mathrm{G} 6$ was reduced by $35 \%$ compared to IgG isotype control, the oocyst intensity of infected mosquitoes fed with $200 \mu \mathrm{g} / \mathrm{ml}$ of $3 \mathrm{G} 6$ was reduced by $42 \%$ compared to IgG isotype controls ( $p$ value $<0.01$ ) (Table 2$)$. The presence of $200 \mu \mathrm{g} / \mathrm{ml}$ of $6 \mathrm{~A} 9$ in an infectious bloodmeal only reduced $P$. falciparum transmission to mosquitoes by $13 \%$, and oocyst intensity was comparable to IgG isotype controls (Table 2).

Further attempts were made to elucidate the precise role of PfPM VII and PfPM X during P. falciparum sexual development and transmission to mosquitoes. Unfortunately, we were unable to produce active, recombinant protease in either an $E$. coli-based expression system or a cell-free wheat germ expression system. The generation of PfPM VII and PfPM X knockout parasites were unsuccessful (Additional files 1, 2).

\section{Discussion}

The data reported here indicate that that PfPM VII and PfPM X are expressed in ookinetes and contribute to $P$. falciparum transmission to Anopheles mosquitoes. This is the first observation that these plasmepsins play an important role in Plasmodium infection of mosquitoes. Transcriptomic data from all the life cycle stages of $P$. falciparum demonstrate mRNA expression of PfPM VII and PfPM X in sexual stage forms. These previously published microarray data were confirmed by RT-PCR on in vitro-cultivated gametocytes, gametes, zygotes and ookinetes and ex vivo-harvested zygotes and ookinetes. Anti-peptide monoclonal antibodies directed against PfPM VII or PfPM X demonstated that these proteins are expressed in sexual stage parasite forms. Interestingly, PfPM VII and PfPM X mRNAs are expressed in P. falciparum gametocytes, but protein was not detected until zygote and gamete development, respectively. This inconsistency between mRNA and protein expression was not explored in this work, but this pattern suggests that PfPM 
Table 1 Effect of mAbs against PfPM VII on Plasmodium falciparum infectivity to Anopheles stephensi mosquitoes

\begin{tabular}{|c|c|c|c|c|}
\hline Exp & Group & $\begin{array}{l}\text { Intensity (geometric } \\
\text { mean oocysts/mosquito) }\end{array}$ & $\begin{array}{l}\text { Oocyst } \\
\text { range }\end{array}$ & $\begin{array}{l}\text { Prevalence (no. infected/total } \\
\text { engorged mosquitoes) }\end{array}$ \\
\hline \multirow[t]{4}{*}{1} & $200 \mu \mathrm{g} / \mathrm{ml} \lg \mathrm{G}$ negative & 2.28 & $0-10$ & $31 / 39(79.5 \%)$ \\
\hline & $200 \mu \mathrm{g} / \mathrm{ml} 1 \mathrm{~B} 4$ & $0.07^{*}$ & $0-2$ & 3/37 (8.1\%) \\
\hline & $400 \mu \mathrm{g} / \mathrm{ml} \mathrm{lgG}$ negative & 22.18 & $7-58$ & 24/24 (100 \%) \\
\hline & $400 \mathrm{ug} / \mathrm{ml} 2 \mathrm{~B} 1$ & $7.7^{*}$ & $0-54$ & 13/17 (76.5 \%) \\
\hline \multirow[t]{4}{*}{2} & $200 \mu \mathrm{g} / \mathrm{ml} \mathrm{lgG}$ negative & 24.23 & $0-121$ & $34 / 40(85.0 \%)$ \\
\hline & $200 \mu \mathrm{g} / \mathrm{ml} 1 \mathrm{~B} 4$ & $3.47^{*}$ & $0-45$ & $20 / 40(50.0 \%)$ \\
\hline & $400 \mu \mathrm{g} / \mathrm{ml} \mathrm{lgG}$ negative & 9.15 & $0-88$ & 29/38 (76.3 \%) \\
\hline & $400 \mu \mathrm{g} / \mathrm{ml} 2 \mathrm{~B} 1$ & $3.17^{*}$ & $0-81$ & 20/33 (66.6\%) \\
\hline \multirow[t]{4}{*}{3} & $200 \mu \mathrm{g} / \mathrm{ml} \lg \mathrm{G}$ negative & 12.67 & $0-55$ & $35 / 40(87.5 \%)$ \\
\hline & $200 \mu \mathrm{g} / \mathrm{ml} 1 \mathrm{~B} 4$ & $2.41^{*}$ & $0-29$ & 8/19 (42.1\%) \\
\hline & $400 \mu \mathrm{g} / \mathrm{ml} \mathrm{lgG}$ negative & 14.74 & $0-68$ & $31 / 32(96.9 \%)$ \\
\hline & $400 \mu \mathrm{g} / \mathrm{ml} 2 \mathrm{~B} 1$ & $6.5^{*}$ & $0-65$ & 29/34 (85.3\%) \\
\hline
\end{tabular}

mAbs and lgG isotype control data from three independent SMFAs. Transmission-blocking activities measured as effects on intensity and prevalence.

* Statistical significance determined by Mann-Whitney $U$ test, control versus $m A b, p$ value $\leq 0.01$

Table 2 Effect of mAbs against PfPM X on Plasmodium falciparum infectivity to Anopheles gambiae mosquitoes

\begin{tabular}{llll}
\hline Group & $\begin{array}{l}\text { Intensity } \\
\text { (geometric } \\
\text { mean oocysts/ } \\
\text { mosquito) }\end{array}$ & Oocyst range & $\begin{array}{l}\text { Prevalence } \\
\text { (no. infected/ } \\
\text { total engorged } \\
\text { mosquitoes) }\end{array}$ \\
\hline $\begin{array}{c}200 \mu \mathrm{g} / \mathrm{ml} \mathrm{lgG} \\
\text { negative }\end{array}$ & 2.6 & $0-55$ & $62 / 80(77.5 \%)$ \\
$100 \mu \mathrm{g} / \mathrm{ml} \mathrm{3G6}$ & 1.7 & $0-108$ & $48 / 80(60.0 \%)$ \\
$200 \mu \mathrm{g} / \mathrm{ml} \mathrm{3G6}$ & $1.5^{*}$ & $0-148$ & $34 / 76(44.7 \%)$ \\
$200 \mu \mathrm{g} / \mathrm{ml} \mathrm{6A9}$ & 2.4 & $0-59$ & $33 / 51(64.7 \%)$ \\
\hline
\end{tabular}

mAbs and IgG isotype control data from triplicate SMFAs under the same conditions, data combined. Transmission-blocking activities measured as effects on intensity and prevalence

* Statistical significance determined by Mann-Whitney $U$ test, control versus $\mathrm{mAb}, p$ value $\leq 0.01$

VII and PfPM X protein expression may be regulated by translational repression, a mechanism used to regulate other Plasmodium sexual stage proteins [53-58]. Similar observations have been seen with Pfs 25 and chitinase, whose mRNAs but not proteins have been detected in gametocytes [50, 59].

Another mechanism to regulate protease activity is zymogen processing. Plasmepsins are known to harbour a proenzyme domain that functions to maintain the enzyme in a catalytically inactive state. Plasmepsins only become catalytically active when the proenzyme domain is cleaved and separated from the catalytic domain. Both PfPM VII and PfPM X contain predicted proenzyme domains. Western immunoblot of all three mAbs targeting PfPM VII only detected one protein in parasite lysate; this finding was unexpected as PfPM VII also contains a predicted proenzyme domain. Additionally, the protein recognized is smaller than the predicted size of the fulllength enzyme but large than the predicted size of the PfPM VII catalytic domain. Although we would expect to see two bands corresponding to the full-length protein and the proenzyme domain alone, it is possible that PfPM VII is not processed and activated in the ookinete. If PfPM VII is secreted or cell-surface associated, a hypothesis not currently supported by IFA or immunoelectron data, it is possible that proenzyme domain is cleaved outside of the parasite. Given this result, it is likely that the full-length protein is processed at a site upstream of the $\mathrm{mAb}$ target region but that the proenzyme domain has not yet been cleaved in the ookinete, resulting in a smaller-than expected full-length protein. Western immunoblot analysis demonstrated that 6A9, which targets the PfPM X proenzyme domain, recognized proteins consistent with the sizes of the full-length enzyme and the cleaved pro-enzyme domain while 3G6, which targets the catalytic domain, recognized proteins consistent with the sizes of the full-length enzyme and the cleaved catalytic domain. This observation suggests that PfPM X is processed, and potentially catalytically active, during $P$. falciparum sexual stage development. Western immunoblot demonstrate that both PfPM VII and PfPM X are processed, and that PfPM X is likely catalytically active in the ookinete.

The majority of proteins that are both important for Plasmodium transmission to mosquitoes and good targets for transmission-blocking vaccines are either localized to the parasite cell surface or secreted from the ookinete. Cell-surface proteins, such as P25/P28, mediate parasite-host interactions and may be essential components of signalling-pathways important for ookinete motility $[15,19,21,60]$. Similarly, ookinete-secreted 
proteins and enzymes, such as chitinase, CTRP and WARP, modify the mosquito midgut environment to allow Plasmodium invasion and infection of the mosquito midgut [13, 14, 17, 18]. Neither PfPM VII nor PfPM $\mathrm{X}$ localized to the parasite cell surface or micronemes. IFA and immunoelectron microscopy demonstrated diffuse cytoplasmic localization of mAbs directed against PfPM VII and PfPM X.

Previous studies showed that pepstatin A, an aspartic protease-specific inhibitor, ALLN and ALLM, two plasmepsin convertase inhibitors, interrupted Plasmodium transmission to mosquitoes [38]. The presence of antibodies directed against PfPM VII or PfPM X significantly reduced $P$. falciparum infection of Anopheles. However, relatively high concentrations of 1B4, 2B1 and 3G6 were required to achieve an effect. It is possible that the antibodies had low affinity, resulting in the low level of interruption of the transmission. It is also possible that these Plasmepsins were important, but not essential, for $P$. falciparum transmission to Anopheles mosquitoes, consistent with previous reports with a $P$. berghei Plasmepsin VII knockout mutant [61]. Equally, if not more likely is the possibility that loss of PfPM VII or PfPM X function in the presence of $\mathrm{mAb}$ was compensated for by the action of related proteases, such as Plasmepsin IX, which are similarly upregulated in sexual stage parasite forms [29]. The equivocal result seen in SMFAs using 6A9, directed against the PfPM X proenzyme domain, is expected if the proenzyme domain of PfPM X is cleaved and no longer associated with the activated catalytic domain in ookinetes. These data indicate that there is still much to learn about the role of plasmepsins in Plasmodium transmission to mosquitoes. Further work is needed to explore these interesting possibilities.

\section{Conclusions}

Knowledge of the Plasmodium sexual cycle and the molecular mechanisms underlying ookinete invasion of the mosquito midgut is essential for understanding parasite developmental programmes and parasite-mosquito interactions. In this study, we have investigated the expression and functional significance of PfPM VII and PfPM X in malaria transmission to mosquitoes. We demonstrated that these proteins are expressed in $P$. falciparum ookinetes and that antibodies directed against these proteins reduced parasite transmission to Anopheles mosquitoes when used at high concentration in mosquito infection experiments. This observation suggests that PfPM VII and PfPM X facilitate Plasmodium infection of mosquitoes. This data complements discoveries demonstrating that $P$. gallinaceum plasmepsin IV was important for parasite infection of the mosquito vector [38] and P. berghei plasmepsin VII was dispensable in its life cycle [61]. Together, these results suggest that plasmepsins expressed in the Plasmodium ookinete function in ways distinct from plasmepsins expressed in asexual parasites. These findings raise a number of interesting questions. What other plasmepsins are expressed in sexual stage parasites? If these plasmepsins are involved in midgut invasion or sexual stage parasite development, what pathways are involved? Further investigation of the role(s) of plasmepsins during sexual development and invasion of mosquitoes will likely lead to novel insights into Plasmodium biology and provide new targets for transmission-blocking vaccines.

\section{Additional files}

Additional file 1. Production of active rPfPM VII and rPfPM X could not be achieved using multiple expression systems.

Additional file 2. PfPM VII and PfPM X appear to be essential for P. falciparum asexual development.

\section{Abbreviations}

PfPM VII: Plasmodium falciparum plasmepsin VII; PfPM X: Plasmodium falciparum plasmepsin X; RT-PCR: reverse transcriptase polymerase chain reaction; SMFA: standard membrane feeding assay; Pfs 25: Plasmodium falciparum 25 kDa surface molecule; IFA: immunofluorescence assay; ELISA: enzymelinked immunosorbent assay; mAb: monoclonal antibody.

\section{Authors' contributions}

FL and VB designed and carried out molecular studies, mosquito feeding assays and statistical analysis, and drafted the manuscript. KP carried out recombinant protein activity assays and helped draft the manuscript. JMV conceived of the study, and directed its design, coordinated the work and finalized the manuscript. All authors have read and approved the final manuscript.

\section{Acknowledgements}

The authors thank SL Hoffman for this NF54 strain of P. falciparum, AA James for providing A. gambiae mosquitoes. We thank T Tsuboi for producing rPfPM VII and rPfPM X using the cell-free wheat germ expression system, MG Farquhar and K Kudlicka, Core Electron Microscopy Facility (funded by the US Public Health Service grants listed). We thank DA Fidock for advice with genetic knockout technology. We thank $\mathrm{A}$. Lubar for figure revisions and $\mathrm{M}$. Matthias for helping draft the manuscript. The funding agencies had no role in the design, collection, analysis, or interpretation of data; in the writing of the manuscript; or in the decision to submit the manuscript for publication.

\section{Competing interests}

The authors declare that they have no competing interests.

Received: 31 May 2015 Accepted: 10 February 2016

Published online: 24 February 2016

\section{References}

1. WHO: World Malaria Report 2015. Geneva, World Health Organization; 2015

2. malERA Consultative Group on Vaccines. A research agenda for malaria eradication: vaccines. PLoS Med. 2011;8:e1000398.

3. Nunes JK, Woods C, Carter T, Raphael T, Morin MJ, Diallo D, et al. Development of a transmission-blocking malaria vaccine: progress, challenges, and the path forward. Vaccine. 2014;32:5531-9. 
4. DeWeerdt S. Vaccines: the take-home lesson. Nature. 2012;484:S24-5.

5. Kaslow DC. Transmission-blocking vaccines. Chem Immunol. 2002;80:287-307.

6. Sinden RE, Canning EU, Bray RS, Smalley ME. Gametocyte and gamete development in Plasmodium falciparum. Proc R Soc Lond B. 1978:201:375-99.

7. Sinden RE, Hartley RH, King NJ. Gametogenesis in Plasmodium; the inhibitory effects of anticytoskeletal agents. Int J Parasitol. 1985;15:211-7.

8. Sinden RE, Billingsley PF. Plasmodium invasion of mosquito cells: hawk or dove? Trends Parasitol. 2001;17:209-12.

9. Baton LA, Ranford-Cartwright LC. Spreading the seeds of million-murdering death: metamorphoses of malaria in the mosquito. Trends Parasitol. 2005;21:573-80.

10. Siden-Kiamos I, Louis C. Interactions between malaria parasites and their mosquito hosts in the midgut. Insect Biochem Mol Biol. 2004;34:679-85.

11. Poudel SS, Newman RA, Vaughan JA. Rodent Plasmodium: population dynamics of early sporogony within Anopheles stephensi mosquitoes. J Parasitol. 2008;94:999-1008.

12. Sinden RE, Billingsley PF. Plasmodium invasion of mosquito cells: hawk or dove? Trends Parasitol. 2001;17:209-11.

13. Vinetz JM, Valenzuela JG, Specht CA, Aravind L, Langer RC, Ribeiro JM, et al. Chitinases of the avian malaria parasite Plasmodium gallinaceum, a class of enzymes necessary for parasite invasion of the mosquito midgut. J Biol Chem. 2000;275:10331-41

14. Li F, Patra KP, Vinetz JM. An anti-chitinase malaria transmission-blocking single-chain antibody as an effector molecule for creating a Plasmodium falciparum-refractory mosquito. J Infect Dis. 2005;192:878-87.

15. Dessens JT, Beetsma AL, Dimopoulos G, Wengelnik K, Crisanti A, Kafatos FC, et al. CTRP is essential for mosquito infection by malaria ookinetes. EMBO J. 1999;18:6221-7.

16. Nacer A, Underhill A, Hurd $\mathrm{H}$. The microneme proteins CTRP and SOAP are not essential for Plasmodium berghei ookinete to oocyst transformation in vitro in a cell free system. Malar J. 2008;7:82.

17. Yuda M, Yano K, Tsuboi T, Torii M, Chinzei Y. von Willebrand Factor A domain-related protein, a novel microneme protein of the malaria ookinete highly conserved throughout Plasmodium parasites. Mol Biochem Parasitol. 2001;116:65-72.

18. Li F, Templeton TJ, Popov V, Comer JE, Tsuboi T, Torii M, Vinetz JM Plasmodium ookinete-secreted proteins secreted through a common micronemal pathway are targets of blocking malaria transmission. J Biol Chem. 2004;279:26635-44.

19. Duffy PE, Kaslow DC. A novel malaria protein, Pfs 28 , and Pfs 25 are genetically linked and synergistic as falciparum malaria transmission-blocking vaccines. Infect Immun. 1997;65:1109-13.

20. Gregory JA, Li F, Tomosada LM, Cox CJ, Topol AB, Vinetz JM, et al. Algaeproduced Pfs 25 elicits antibodies that inhibit malaria transmission. PLoS One. 2012;7:e37179.

21. Dessens JT, Siden-Kiamos I, Mendoza J, Mahairaki V, Khater E, Vlachou $\mathrm{D}, \mathrm{Xu}$ XJ, et al. SOAP, a novel malaria ookinete protein involved in mosquito midgut invasion and oocyst development. Mol Microbiol. 2003;49:319-29.

22. Kadota K, Ishino T, Matsuyama T, Chinzei Y, Yuda M. Essential role of membrane-attack protein in malarial transmission to mosquito host. Proc Natl Acad Sci. 2004;101:16310-5.

23. Huber M, Cabib E, Miller LH. Malaria parasite chitinase and penetration of the mosquito peritrophic membrane. Proc Natl Acad Sci. 1991;88:2807-10.

24. Sieber KP, Huber M, Kaslow D, Banks SM, Torii M, Aikawa M, et al. The peritrophic membrane as a barrier: its penetration by Plasmodium gallinaceum and the effect of a monoclonal antibody to ookinetes. Exp Parasitol. 1991;72:145-56.

25. Han YS, Thompson J, Kafatos FC, Barillas-Mury C. Molecular interactions between Anopheles stephensi midgut cells and Plasmodium berghei: the time bomb theory of ookinete invasion of mosquitoes. EMBO J. 2000;19:6030-40.

26. Eksi S, Czesny B, Greenbaum DC, Bogyo M, Williamson KC. Targeted disruption of Plasmodium falciparum cysteine protease, falcipain 1, reduces oocyst production, not erythrocytic stage growth. Mol Microbiol. 2004;53:243-50.

27. Aly AS, Matuschewski K. A malarial cysteine protease is necessary for Plasmodium sporozoite egress from oocysts. J Exp Med. 2005;202:225-30.
28. Blackman MJ. Malarial proteases and host cell egress: an 'emerging' cascade. Cell Microbiol. 2008;10:1925-34.

29. Zhou Y, Ramachandran V, Kumar KA, Westenberger S, Refour P, Zhou B. Evidence-based annotation of the malaria parasite's genome using comparative expression profiling. PLoS One. 2008;3:e1570.

30. Coombs GH, Goldberg DE, Klemba M, Berry C, Kay J, Mottram JC. Aspartic proteases of Plasmodium falciparum and other parasitic protozoa as drug targets. Trends Parasitol. 2001;17:532-7.

31. Francis SE, Gluzman IY, Oksman A, Knickerbocker A, Mueller R, Bryant ML, et al. Molecular characterization and inhibition of a Plasmodium falciparum aspartic hemoglobinase. EMBO J. 1994;13:306-17.

32. Gluzman IY, Francis SE, Oksman A, Smith CE, Duffin KL, Goldberg DE. Order and specificity of the Plasmodium falciparum hemoglobin degradation pathway. J Clin Invest. 1994;93:1602-8.

33. Wyatt DM, Berry C. Activity and inhibition of plasmepsin IV, a new aspartic proteinase from the malaria parasite Plasmodium falciparum. FEBS Lett. 2002;513:159-62.

34. Banerjee R, Liu J, Beatty W, Pelosof L, Klemba M, Goldberg DE. Four plasmepsins are active in the Plasmodium falciparum food vacuole, including a protease with an active-site histidine. Proc Natl Acad Sci. 2002;99:990-5.

35. Le Bonniec S, Deregnaucourt C, Redeker V, Banerjee R, Grellier P, Goldberg $D E$, et al. Plasmepsin II, an acidic hemoglobinase from the Plasmodium falciparum food vacuole, is active at neutral $\mathrm{pH}$ on the host erythrocyte membrane skeleton. J Biol Chem. 1999;274:14218-23.

36. Klemba M, Goldberg DE. Characterization of plasmepsin V, a membranebound aspartic protease homolog in the endoplasmic reticulum of Plasmodium falciparum. Mol Biochem Parasitol. 2005;143:183-91.

37. Ecker A, Bushell ES, Tewari R, Sinden RE. Reverse genetics screen identifies six proteins important for malaria development in the mosquito. Mol Microbiol. 2008;70:209-20.

38. Li F, Patra KP, Yowell CA, Dame JB, Chin K, Vinetz JM. Apical surface expression of aspartic protease plasmepsin 4, a potential transmission-blocking target of the Plasmodium ookinete. J Biol Chem. 2010;285:8076-83.

39. Read M, Hyde JE. Simple in vitro cultivation of the malaria parasite Plasmodium falciparum (erythrocytic stages) suitable for large-scale preparations. Methods Mol Biol. 1993;21:43-55.

40. Ifediba T, Vanderberg JP. Complete in vitro maturation of Plasmodium falciparum gametocytes. Nature. 1981;294:364-6.

41. Trager W, Jensen JB. Human malaria parasites in continuous culture. Science. 1976;193:673-5

42. Bounkeua V, Li F, Vinetz JM. In vitro generation of Plasmodium falciparum ookinetes. Am J Trop Med Hyg. 2010;83:1187-94.

43. Dinglasan RR, Alaganan A, Ghosh AK, Saito A, van Kuppevelt TH, JacobsLorena M. Plasmodium falciparum ookinetes require mosquito midgut chondroitin sulfate proteoglycans for cell invasion. Proc Natl Acad Sci U S A. 2007;104:15882-7.

44. Ghosh AK, Dinglasan RR, Ikadai H, Jacobs-Lorena M. An improved method for the in vitro differentiation of Plasmodium falciparum gametocytes into ookinetes. Malar J. 2010;9:194.

45. Gerberg EJ, Barnard DR, Ward RA, American Mosquito Control Association. Manual for mosquito rearing and experimental techniques. Rev. edn. Lake Charles, La.: American Mosquito Control Association; 1994.

46. LaVallie ER, McCoy JM. Gene fusion expression systems in Escherichia coli. Curr Opin Biotechnol. 1995;6:501-6.

47. Hellman U, Wernstedt C, Gonez J, Heldin CH. Improvement of an "In-Gel" digestion procedure for the micropreparation of internal protein fragments for amino acid sequencing. Anal Biochem. 1995;224:451-5.

48. Rosenfeld J, Capdevielle J, Guillemot JC, Ferrara P. In-gel digestion of proteins for internal sequence analysis after one- or two-dimensional gel electrophoresis. Anal Biochem. 1992;203:173-9.

49. De Vries L, Elenko E, McCaffery JM, Fischer T, Hubler L, McQuistan T, et al. RGS-GAIP, a GTPase-activating protein for Galphai heterotrimeric G proteins, is located on clathrin-coated vesicles. Mol Biol Cell. 1998;9:1123-34.

50. Vinetz JM, Dave SK, Specht CA, Brameld KA, Xu B, Hayward R, et al. The chitinase PfCHT1 from the human malaria parasite Plasmodium falciparum lacks proenzyme and chitin-binding domains and displays unique substrate preferences. Proc Natl Acad Sci. 1999;96:14061-6.

51. Carter R, Ranford-Cartwright L, Alano P. The culture and preparation of gametocytes of Plasmodium falciparum for immunochemical, molecular, and mosquito infectivity studies. Methods Mol Biol. 1993;21:67-88. 
52. Sinden RE. The biology of Plasmodium in the mosquito. Experientia. 1984;40:1330-43.

53. Mair GR, Lasonder E, Garver LS, Franke-Fayard BM, Carret CK, Wiegant JC, et al. Universal features of post-transcriptional gene regulation are critical for Plasmodium zygote development. PLoS Pathog. 2010;6:e1000767.

54. Braks JA, Mair GR, Franke-Fayard B, Janse CJ, Waters AP. A conserved U-rich RNA region implicated in regulation of translation in Plasmodium female gametocytes. Nucleic Acids Res. 2008;36:1176-86.

55. Kooij TW, Matuschewski K. Triggers and tricks of Plasmodium sexual development. Curr Opin Microbiol. 2007;10:547-53.

56. Mair GR, Braks JA, Garver LS, Wiegant JC, Hall N, Dirks RW, et al. Regulation of sexual development of Plasmodium by translational repression. Science. 2006;313:667-9.

57. del Carmen Rodriguez M, Gerold P, Dessens J, Kurtenbach K, Schwartz RT, Sinden RE, et al. Characterisation and expression of pbs25, a sexual and sporogonic stage specific protein of Plasmodium berghei. Mol Biochem Parasitol. 2000;110:147-59.
58. Paton MG, Barker GC, Matsuoka H, Ramesar J, Janse CJ, Waters AP, et al. Structure and expression of a post-transcriptionally regulated malaria gene encoding a surface protein from the sexual stages of Plasmodium berghei. Mol Biochem Parasitol. 1993;59:263-75.

59. Pradel G, Hayton K, Aravind L, lyer LM, Abrahamsen MS, Bonawitz A, et al. A multidomain adhesion protein family expressed in Plasmodium falciparum is essential for transmission to the mosquito. J Exp Med. 2004;199:1533-44.

60. Siden-Kiamos I, Vlachou D, Margos G, Beetsma A, Waters AP, Sinden RE, et al. Distinct roles for pbs21 and pbs 25 in the in vitro ookinete to oocyst transformation of Plasmodium berghei. J Cell Sci. 2000;113(Pt 19):3419-26.

61. Mastan BS, Kumari A, Gupta D, Mishra S, Kumar KA. Gene disruption reveals a dispensable role for plasmepsin VII in the Plasmodium berghe life cycle. Mol Biochem Parasitol. 2014;195:10-3.

\section{Submit your next manuscript to BioMed Central and we will help you at every step:}

- We accept pre-submission inquiries

- Our selector tool helps you to find the most relevant journal

- We provide round the clock customer support

- Convenient online submission

- Thorough peer review

- Inclusion in PubMed and all major indexing services

- Maximum visibility for your research

Submit your manuscript at www.biomedcentral.com/submit
() BioMed Central 